NBER WORKING PAPER SERIES

MONETARY POLICY STRATEGIES

Robert Flood

Peter Isard

Working Paper No. 2770

NATIONAL BUREAU OF ECONOMIC RESEARCH

1050 Massachusetts Avenue

Cambridge, MA 02138

November 1988

This research is part of NBER's research program in International studies. Any opinions expressed are those of the authors not those of the National Bureau of Economic Research. 
NBER Working Paper \#2770

November 1988

\section{MONETARY POLICY STRATEGIES}

\section{ABSTRACT}

The paper considers the merits of rules and discretion for monetary policy when the structure of the macroeconomic model and the probability distributions of disturbances are not well defined. It is argued that when it is costly to delay policy reactions to seldom-experienced shocks until formal algorithmic learning has been accomplished, and when time consistency problems are significant, a mixed strategy that combines a simple verifiable rule with discretion is attractive. The paper also discusses mechanisms for mitigating credibility problems and emphasizes that arguments against various types of simple rules lost their force under a mixed strategy.

Robert Flood Research Department International Monetary Fund Washington, DC 20431
Peter Isard

Research Department

International Monetary Fund

Washington, DC 20431 
Robert Flood

Peter Isard 1

\section{Monetary Policy Strategies}

I. Introduction

Although the major industrial countries have experimented with different strategies for monetary policy since the mid-1970s, a number of basic issues remain unresolved. These issues include: (1) the importance of monetary policy credibility and the roles for rules and discretion; (2) the relative attractiveness of monetary growth rates, exchange rates, and other variables as targets or objectives for policy; and (3) the appropriate degree of complexity to incorporate into statecontingent procedures for adjusting the settings of policy instruments in response to new information about the economy.

This paper addresses these and other issues that are basic to the design and implementation of policy strategies in practice. The paper begins by developing a simple analytic framework that can be used to compare the implications of different monetary policy strategies for an open economy in which social welfare depends negatively on both price level instability and deviations of output from its full employment level (Section II). Under the assumptions that the structure of the economic model is known and that disturbances to the economy can be characterized as having well-defined probability distributions, three alternative policy strategies are compared (Section III). These strategies are:

1. We thank Kenneth Rogoff for helping us formulate issues at an early stage and Elhanen Helpman and Dale Henderson for valuable reactions and discussions. However, they should neither be blamed for, nor assumed to agree completely with, our views. 
(1) discretion, (2) the optimal non-state-contingent rule for monetary growth, and (3) the optimal state contingent rule for monetary growth. The paper then turns to issues arising from uncertainty about the structure and parameters of the macroeconomic model and the nature of economic disturbances (Section IV). Although it is possible to use new information to continuously re-evaluate the model in a systematic manner, and to specify well-defined procedures for adjusting the settings of monetary policy instruments in response to new information, it would be difficult for society to monitor compliance with a complicated statecontingent policy strategy in the context of period-by-period revisions in the estimated macroeconomic model. Moreover it may be costly or impossible to learn much quickly about the nature of seldom-experienced disturbances, and delaying policy reactions until formal, algorithmic, learning has been accomplished may be very costly to society. Thus, in the presence of distortions that generate time-inconsistent incentives for the monetary authorities, attempts to rely on a complicated statecontingent strategy could give rise to credibility problems.

While the problems associated with complicated state-contingent strategies have led some economists to propose the adoption of simple monetary rules, this paper shows that the strategy of mixing a simple rule with discretion can be preferable both to rigid adherence to the rule and to complete discretion (Section V). The paper also discusses the role of institutional arrangements for mitigating monetary policy credibility problems (Section VI) and the choice of variables for simple monetary rules (Section VII). It is emphasized that the relative merits of different choices of variables for a monetary rule may depend on 
whether the policy strategy calls for rigid adherence to the rule or for mixing the rule with discretion. A final section provides concluding remarks.

\section{The Analytic Framework}

This section develops a simple analytic framework that sheds light on a number of issues that arise in adopting a monetary policy strategy for an open economy. Following conventional practice, we consider an economy in which society dislikes deviations of output from its full employment level and also dislikes price level instability. In this context, it is assumed for simplification that the objective of monetary policy is to minimize the loss function:

(1) $\phi_{t}=\left(y_{t}-\bar{y}\right)^{2}+\alpha\left(p_{t}-p_{t-1}\right)^{2} \quad, \alpha>0$,

where $y_{t}$ is the logarithm of output in period $t, \bar{y}$ is the logarithm of full employment output, $p_{t}$ is the logarithm of the price level, and $\alpha$ is a strictly positive weight that society places on price level stabilization relative to output stabilization. $1 /$

Following Gray (1976), Canzoneri (1985) and others, we assume that output is produced by labor, that the nominal wage rate is set in a contract negotiated prior to the realization of the price level, and that the employment contract calls for workers to supply whatever amount of

1) We abstract, in our single-period optimization from issues involving "reputation" of the policymaker. For a survey of issues concerning reputation, see Rogoff (1987). 
labor is demanded by firms at the negotiated wage rate. These assumptions are taken to imply that, in combination, the production function and the labor demand function yield a relationship in which output is a decreasing function of the real cost of a unit of labor:

(2) $y_{t}=d \cdot c\left(w_{t}-p_{t}\right)+\mu_{t}$

Here, $w_{t}$ is the logarithm of the wage rate, $c$ and $d$ are parameters, and $\mu_{t}$ is a mean zero productivity shock. 1 / It is also convenient to assume that wage setters know the output supply function and act to minimize the expected squared deviation of output (employment) from some implicit target level $(\bar{y})$ that may differ from the full employment concept that enters the social loss function. $2 /$ Thus, the wage level is determined from the first order condition

$$
\text { (3) } \frac{\partial}{\partial w_{t}} E_{t-1}\left(y_{t}-\tilde{y}\right)^{2}=0
$$

which, together with (2), implies

(4) $w_{t}=E_{t-1} P_{t}+\frac{d-\tilde{y}}{c}$

1) Assuming that the logarithm of the production function is $y_{t}-\lambda+\theta l_{t}+x_{t}$, where $l_{t}$ is the logarithm of labor input, $x_{t}$ is the shock to the production function and $0<\theta<1$, then $\mu_{t}-x_{t} /(1-\theta)$.

2/ See Rogoff (1985) for one possible elaboration of this approach. Rogoff defines $\vec{y}$ as the level of output (employment) that would arise if contracts could be negotiated after observing the productivity shock and all other period $t$ information. 
Substitution of (4) into (2) yields an output supply relationship:

(5) $y_{t}-\bar{y}+c\left(P_{t}-E_{t-1 P t}\right)+\mu_{t}$,

which is similar to the standard rational expectations supply function introduced by Lucas (1972). Substitution of (5) into (1) implies

(6) $\quad \phi_{t}=\left[c\left(p_{t}-E_{t-1 P_{t}}\right)-\kappa+\mu_{t}\right]^{2}+\alpha\left[p_{t}-p_{t-1}\right]^{2}$

or

(7) $\phi_{t}=\left[c\left(\pi_{t}-E_{t-1, \pi_{t}}\right)-\kappa+\mu_{t}\right]^{2}+\alpha \pi_{t}^{2}$

where $\pi_{t}=\mathrm{Pt}_{t}-\mathrm{Pt}_{\mathrm{t}-1}$ is the rate of inflation and

(8) $\kappa=\bar{y}-\bar{y}$

is the difference between the social concept of full employment output and the level of output that wage setters implicitly target when negotiating their wage contracts. The existence of "distortions" such as unemployment compensation or income taxation--or of incentives for wage setters to maximize the welfare of some subset of the labor force that is 
already employed (or that has seniority rights to employment)--may give rise to a situation in which $\kappa$ is positive.

To address monetary policy issues for an open economy, it is convenient to use the relationship:

(9) $\pi_{t}-\pi_{t}^{*}+s_{t}+\phi_{t}$

where $\pi_{t}{ }^{*}$ is the foreign rate of inflation, $s_{t}$ is the rate of change of the nominal exchange rate (the rate of change of the domestic currency price of foreign exchange), and $\phi_{t}$ is a shock to the purchasing power parity relation. It is assumed that monetary authorities control basemoney growth and that the nominal rate of depreciation of the domestic currency can be decomposed into one component that varies systematically with the differential between domestic base-money growth rate $\left(b_{t}\right)$ and the foreign inflation $\left(\pi_{\mathrm{t}}^{*}\right)$, a second component $\left(\phi_{t}\right)$ reflecting the purchasing power parity shocks, and a third part $\left(v_{t}\right)$ that refiects other elements responsible for nominal exchange rate movements. This relationship is given by: 1

(10) $s_{t}-b_{t}-\pi_{t}^{*}-\phi_{t}+v_{t}$

1) The formulation is intended to be a stripped-down version of a flex-price mode1. 
To simplify the later algebra, it is assumed that $E_{t-1} v_{t}=0$. Thus, under the additional assumptions that $v_{t}$ is exogenous to domestic policy and uncorrelated with $\mu_{t}, \underline{1} /$ and the distortion term $(x)$ is time and policy invariant, equations (9) and (10) can be combined to yield: $\underline{2}$

(11) $\pi_{t}-b_{t}+v_{t}$

and

(12) $\psi_{t}-\left[c\left(b_{t}+v_{t}-E_{t-1} b_{t}\right)-x+\mu_{t}\right]^{2}+\alpha\left[b_{t}+v_{t}\right]^{2}$

To simplify notation further, it is convenient to transform variables and to express the policy problem as that of minimizing the social loss function

(13) $I_{t}=\left(b_{t}+v_{t}-E_{t-1} b_{t}-k+u_{t}\right)^{2}+a\left(b_{t}+v_{t}\right)^{2}$

where $L_{t}=\psi_{t} / c^{2}, k-\kappa / c, u_{t}=\mu_{t} / c$, and $a=\alpha / c^{2}$.

Note that while our primary interest lies in analyzing monetary policy for an open economy, equations (11) - (13) apply not only to an

1) Allowing correlations between the various shocks would introduce covariances into our later analysis, but would not change any of our basic points. We have refrained from analyzing exchange rate regimes in our setup because of the key role played in exchange rate regime choice literature by the covariances we are assuming away.

2) While our main points are robust to many relaxations of the white noise and independence assumptions about the shocks, things would be much more complicated in the realistic setting where the coefficient on $b_{t}$ in equation (10) was not known with certainty. 
open economy with stochastic terms in the purchasing power parity relation and the nominal exchange rate equation, but also to a closed economy with white noise in the relationship between inflation and basemoney growth.

\section{III: Comparisons of Alternative Strategies}

The analytic framework developed in the previous section will now be used to compare social welfare--as measured by the expected value of the social loss function--under (1) a strategy of monetary discretion, (2) the optimal non-state-contingent rule for money growth, and (3) the optimal state contingent rule for monetary growth. 1 It should be emphasized that in any discussion of the optimal design of monetary policy, a central consideration is the extent to which the structure of the macroeconomic model is known, the relevant economic variables are observable, and the disturbances to the economy can be characterized in terms of well-defined probability distributions. In this section it is assumed that both the monetary authority and the private sector know the macroeconomic structure, can deduce $u_{t}$ and $v_{t}$ from observable variables and their knowledge of the parameters of the model ex post, and have accurate ex ante information about the probability distributions from which $u_{t}$ and $v_{t}$ are drawn.

\section{Discretion}

Under discretion, the monetary authority sets $b_{t}$ to minimize (13) subject to the observed values of $u_{t}$ and $v_{t}$, and, most importantly,

1) In a companion paper, we include a fixed exchange rate among the monetary policies that we study. Such a consideration is not pursued presently because we have assumed $v_{t}$ and $u_{t}$ to be uncorrelated, which removes most of the interesting aspects of exchange rate regime choice. 
subject to a predetermined value of $E_{t-1} \pi_{t}$. The first order condition for a minimum of (14) with respect to $b_{t}$ is:

(14) $b_{t}=-v_{t}+\frac{1}{1+a}\left(E_{t-1} b_{t}+k-u_{t}\right)$.

Private agents understand the monetary authority's motives, so they form their expectations of base-money growth by taking the expectation of $b_{t}$ in equation (14). Combining this expectation with the expectation of equation (11) yields:

(15) $E_{t-1} \pi_{t}=E_{t-1} b_{t}=k / a$

This expression links the inflationary bias that arises under discretion to the distortion term $k$. If $k$ were zero, deviations of output from its full employment level would also be zero in the absence of inflation surprises and productivity shocks (recall conditions (5) and ( 8 )), and there would be no inflationary bias.

To evaluate social welfare, substitute (15) into (14) to obtain:

(16) $b_{t}^{D}-\cdot v_{t}-\frac{u_{t}}{1+a}+\frac{k}{a}$,

where $b_{t}^{D}$ is base growth under discretion. Thus, from (5), the realized loss from discretion is:

(17) $\quad L_{t}^{D}=\frac{(1+a)}{a}\left(-k+\frac{a}{(1+a)} u_{t}\right)^{2}$ 
and the expected loss is:

$$
E_{t-1} L_{t}^{D}=\frac{1+a}{a} k^{2}+\frac{a}{1+a} v(u)
$$

where $V(u)$ is the variance of $u_{t}$ conditional on information from period t-1. 1/ The first term in (18) reflects the expected loss associated with whatever output or labor market distortions are responsible for the inflation bias, while the second term reflects the loss associated with fluctuations in productivity.

\section{The optimal non-state-contingent rule}

Next consider the implications of following a non-state-contingent rule for money growth--that is, a rule in which the setting of $b_{t}$ is independent of expected shocks to the economy as characterized by the disturbances $u_{t}$ and $v_{t}$. Given that the model contains no variables that change predictably over time, one rule that might be considered would set $b_{t}$ equal to that constant $b$ that minimizes the expected value of the loss function when private agents have rational expectations such that $E_{t-1} b_{t}=b$. For such a rule, b would appear only in the second term of the loss function (13), and since a constant $b$ is uncorrelated with the $v_{t}$ shocks, the loss-minimizing rule of this type is $b=0$.

1) We are assuming that policy strategies in this uncertain environment are evaluated using the expectation of the loss function. 
From equation (13), the realized loss from following the optimal non-state-contingent rule is:

(19) $L_{t}^{R}=\left(v_{t}+u_{t}-k\right)^{2}+a v_{t}^{2}$

and the expected loss is:

(20) $E_{t-1} L_{t}^{R}=k^{2}+(1+a) V(v)+v(u)$,

where $V(v)$ is the variance of $v_{t}$.

Now compare (18) and (20). Note that even for the closed economy case with perfect correlation between inflation and base-money growth.that is, for the case $v_{t}=0$ for all $t--$ the preference ordering between discretion and the optimal non-state contingent rule depends on the size of the distortion term relative to the variance of the productivity shock, as well as on the weight that society places on inflation stabilization relative to output stabilization. It is readily apparent that the rule dominates in the nonstochastic case. It is also apparent, however, that discretion becomes increasingly attractive as the variance of the productivity shock increases, and also becomes more attractive as the relationship between the inflation rate and base-money growth becomes noisier (i.e., as $V(v)$ increases). If These comparisons reflect the fact that discretion has the undesirable consequence of generating an inflationary bias whenever there are distortions affecting the determination of output, but also has the desirable consequence of

1) Had we allowed co-variance between $u_{t}$ and $v_{t}$ this conclusion would need to be altered accordingly. 
allowing the monetary authority to offset some of the undesirable effects of either productivity shocks or noise in the relationship between inflation and base-money growth. 1/

\section{The optimal state-contingent rule}

The optimal state-contingent rule for monetary growth is the strategy that mimics the discretion strategy (16) without including a response to the distortion term $k$ : $2 /$

$$
\text { (21) } b_{t}^{s}--v_{t}-\frac{u_{t}}{1+a} \text {, }
$$

Under this rule

$$
L_{t}^{S}=\left[\frac{a u_{t}}{1+a}-k\right]^{2}+a\left[\frac{u_{t}}{1+a}\right]^{2}
$$

and

(23) $E_{t-1} L_{t}^{S}=k^{2}+\frac{a}{1+a} V(u)$

Note from (18) and (20) that this strategy dominates the other strategies we have considered.

1) These comparisons ignore additional "accountability" considerations that might arise to the extent that the central bank may have different preferences than society at large and might not seek to minimize the social loss function if left to its own discretion.

2) From the structure of the model and the assumption of uncorrelated disturbances, it is intuitively clear that the optimal state contingent strategy must have a linear form $b_{t}=\alpha u_{t}+\beta v_{t}$. Under the assumption of model-consistent expectations, it is straightforward to show that the coefficients in (2l) describe the values of $\alpha$ and $\beta$ that minimize the social loss function. 
Note also, however, that while $b_{t}^{S}$ is an optimal rule, it is not a time-consistent discretionary strategy and therefore expectations predicated on it as a strategy are not rational unless the central bank can somehow be precommitted to follow the strategy. 1 / If at time $t-1$, in the absence of limits on central bank discretion, the private sector had believed an announcement that the central bank at time $t$ would follow $b_{t}^{S}$, implying $E_{t-1} b_{t}=E_{t-1} b_{t}^{S}=0$, then it can be shown that for $\delta=k /(1+a), E_{t-1} L_{t}\left(b_{t}^{S}+\delta \mid E_{t-1} b_{t}-0\right)<E_{t-1} L_{t}^{S}$. This would provide a temptation for the monetary authority to increase social welfare by deviating from the announced strategy at time $t$. Consequently, the monetary authority could not achieve $L_{t}^{S}$ under discretion because the $b_{t}^{S}$ strategy would not be credible to market participants who rationally perceived the central bank's incentive to shift from $b_{t}^{S}$ to $b_{t}^{S}+\delta$. Without the ability to precommit to a strategy--i.e., without relinquishing the discretion to deviate from whatever strategy it announced--the minimum expected loss that the monetary authority could achieve would be $E_{t-1} L_{t}^{D}$.

\section{Issues Arising From Uncertainty About the Macroeconomic Model}

If $u_{t}$ and $v_{t}$ were generated by well-understood sources and were observable to the monetary authority and to society, then society could design its institutions to provide strong incentives for the central bank to adhere rigidly to the optimal state contingent rule. The

1) See Kydland and Prescott (1977) and Barro and Gordon (1983). 
precommitment or credibility problem could be solved by making it costly for the monetary authority to deviate from the social optimum.

In practice, however, monetary authorities and private agents must operate with incomplete information, not only about the nature of the shocks that buffet the economy, but also about the responses of output and inflation to different types of shocks. I/ The oil price shocks in the 1970 s were not perfectly understood at the time they were experienced, and the implications for output and inflation of different monetary policy responses to those shocks could not have been predicted with much confidence. $2 /$ The implications of financial innovation and deregulation for the relationship between inflation and (base) money growth is still not well understood. The appropriate monetary policy response to the stock market collapse of October 1987 was, in genera1 terms, widely agreed upon in advance, but the question of how much liquidity to leave in the system after stock prices had stabilized at lower levels could not be answered with much confidence. Similarly, the implications of large changes in exchange rates for output and inflation cannot be predicted with much confidence when the reasons for the exchange rate changes are not well understood.

What type of monetary policy makes the most sense when there is considerable uncertainty about both the structure of the macroeconomic

1) Policymakers are not so concerned about how to respond to oftenexperienced disturbances; they have learned from experience and advice how to make such responses and these responses could be codified into an evolving rule. Indeed, the overlapping tenures of central bank staff contributes to the development of "central bank tradition", which is a form of evolving rule.

2) See Rogoff (1985) for a treatment of some aspects of uncertainty in this setting. 
model and the nature of economic disturbances? In part, the answer depends on whether there is a basis for believing that the time consistency problem is a significant concern.

The reasons for believing that the time consistency problem is indeed a significant concern include not only the existence of unemployment compensation, union bargaining power and a distorting income tax system, but also the fact that monetary policy is conducted in an environment in which different political pressure groups implicitly want the authorities to minimize different loss functions and make strong efforts to influence the choice of central bank governors. The latter fact does not necessarily imply that discretionary monetary policy has induced an inflationary bias in the past. 1/ Rather, it simply recognizes that in a democratic society there are constant political pressures for central banks to make choices that invalidate what market participants had previously been led to expect.

We will assume, accordingly, that we are interested in devising a monetary policy strategy for an economy in which time consistency is indeed a relevant issue, and we will also assume (perhaps heroically) that the parameters of the social loss function are well defined and stable over time. If the economic structure and the probability distributions of economic disturbances were well known, the policy problem could be viewed as a matter of designing institutional mechanisms for overcoming the time consistency problem by credibly precommitting the

1) Many would argue that relative to the monetary rules that some political interest groups might have suggested, the presence of monetary discretion in the major industrial countries has had deflationary consequences during the 1980s. 
monetary authorities to following the optimal state contingent rule. (The use of institutional mechanisms to mitigate monetary policy credibility problems will be discussed in Section VI below.)

We have in mind a situation where the policymaker must operate in an environment containing some aspects quite different than those portrayed in typical economic models. In particular we assume that the policymaker must react to both recurring and nonrecurring events. Even without full information about parameters and distributions, optimal reactions to recurring events can be codified into a rule. For the recurring part of the enviroment new information can be used to continuously re-evaluate.in a systematic and statistically appropriate manner--the structure and structural parameters of the economy and the nature and probability distributions of economic disturbances. Because there may be important gains from allowing the central bank to make use of the latest available information in determining the settings of its policy instruments, this conditioning procedure seems useful and appropriate for feeding information into the day-to-day problems facing the policymaker.

On the other hand there is another part of the policymaker's environment, which is not so amenable to codification of reactions. This part involves seldom-experienced events like wars, commodity-price shocks, asset market panics, or horizon-expanding inventions. The nature of these events makes attempts at policy precommitment prior to the event seem far fetched. 


\section{v. The Strategy of Mixing a Simple Rule with Discretion}

Uncertainty and ignorance about macroeconomic behavior--in combination with time consistency problems-has led some economists to propose simple rules for monetary policy. McCallum (1988, p.3) argues, for example, that "neither theory nor evidence points convincingly to any one of the many competing models of the dynamic interaction between nominal and real variables" and proposes a simple rule that performs well in counterfactual simulation experiments conducted with a variety of structural models of the economy. 1 /

The attractiveness of simple rules is also suggested implicitly by past policy practices, which have included non-state-contingent money growth targets and exchange rate stabilization objectives. It is difficult to imagine that a complicated state contingent rule would be attractive to monetary authorities or politically acceptable to the public at large, although it is relatively easy to imagine that a simple state contingent rule for money growth (e.g., a rule calling explicitly for countercyclical behavior) could be acceptable.

This section of the paper argues that rigid adherence to a simple rule may be inferior to the strategy of mixing a simple rule with discretion. The possible gains from a mixing strategy can be illustrated using the framework built earlier. We presume, to begin with, that society has identified the rule that it wants the central bank to follow in the absence of situations calling for discretion; this rule may be

1/ McCallum's rule prescribes settings for the monetary base that are intended to keep nominal aggregate demand growing smoothly at a noninflationary rate. See Flood and Isard (1988) for an analys is of the McCallum proposal. 
either state contingent or non-state-contingent, as long as it is easy for society to ascertain whether the rule has been followed ex post. To capture the fact that society wants the central bank to exercise discretion only when there are relatively large payoffs in terms of the social loss function, we assume that the central bank has been motivated to minimize the sum of the social loss function L (as specified by condition (13)) plus a cost that arises whenever policy settings deviate from the rule. $1 /$

For purposes of providing a simple illustration, we consider the analytic framework used in Section II under the assumptions that $v_{t}=0$ and that the $u_{t}$ shocks are not well-understood in the sense that neither society nor the policymaker has enough experience with the shocks to parameterize the shock's distribution. For present purposes, $u_{t}$ represents uncertainty. Having simplified the problem by assuming away all of the shocks coming from well-understood distributions, we also assume, consistently, that the rule that society wants the central bank to follow is the optimal non-state-contingent rule $b_{t}^{R}=0.2 /$ We further

1) From the point of view of our example it makes little difference whether society imposes the cost on itself (perhaps in the form of a costly institutional adjustment) or imposes the cost directly on the central bank (perhaps in the form of reduced bonuses or endless Congressional testimony). We adopt the simplest structure by assuming that the cost is imposed on the monetary authority and we assume that the cost is not a deadweight loss to society as a whole. Other examples can be constructed with alternative cost assumptions.

2f In the presence of well-understood shocks, a verifiable state contingent rule would be more attractive. 
assume that the distribution of $u_{t}$ shocks is symmetric, and we consider a threshold size $\theta$ and an associated probability q such that

$$
\left.q=\operatorname{prob}|| u_{t} \mid \leq \theta\right\}
$$

We view $\left\{u_{t}:\left|u_{t}\right|>\theta\right\}$ as a set of "large poorly-understood shocks" to which society would like the monetary authority to respond by overriding the rule. If If society has established the appropriate incentives for the monetary authority (i.e., made the cost of overriding the rule large enough but not too large), then society can expect that the rule will be overridden if, and only if, the shock is large. $2 /$ In this case, it is straightforward to show that for some parameter values the mixed strategy is preferable to (i.e., results in a smaller expected loss than) both the rule and discretion.

The first step in the demonstration is to note that:

$$
E_{t-1} b_{t}=q E_{t-1} b_{t}\left|R+(1-q) E_{t-1} b_{t}\right| D
$$

where $E_{t-1} b_{t} \mid R$ is the period $t-1$ conditional expectation of base money growth given that the rule is being followed, and $E_{t-1} b_{t} \mid D$ is the

1. We recognize that our writing down a parameterization of the $u_{t}$ shocks is in an uneasy tension with our assumption that the shocks come from poorly-understood sources. One possible interpretation of our set up in a modern idiom is that the agents in the model have not converged to rational expectations concerning $u_{t}$. In this environment, with little known about the distribution of $u_{t}$, we would expect considerable disagreement about the parameters in (24).

2) In a companion paper, we show how to set the cost optimally from the perspective of the social loss function both if the social loss includes the cost and if it does not. 
t-1 conditional expectation of $b_{t}$ given discretion. Recalling that $a$ discretionary strategy must satisfy the first order condition (14), it follows that:

(26) $b_{t} \mid D=\frac{1}{1+a}\left(E_{t-1} b_{t}+k-u_{t}\right)$

where we have used $v_{t}=0$. Next, use equation (17) and the condition $b_{t} \mid R=0$ to derive:

$$
\text { (27) } E_{t-1} b_{t} \mid D=\frac{k}{a+q}
$$

The $q$, which is the probability of following the rule, shows up in equation (27) because this scheme modifies agents' rational expectations of base growth. As long as $q$ is positive, the scheme reduces expected base growth conditional on discretion and will therefore reduce the inflationary bias. Unconditional expected base growth, which is obtained from equations (25) and (27), is:

$$
\text { (28) } E_{t-1} b_{t}=\frac{(1-q) k}{a+q}
$$

Next, consider that the expected value of the loss function under the mixed strategy is:

$$
\text { (29) } E_{t-1} L_{t}^{M}=q E_{t-1} L_{t}^{R M}+(1-q) E_{t-1} L_{t}^{D M}
$$


where $L_{t}^{M}$ is the loss under the mixed strategy, $L_{t}^{R M}$ is the loss if the rule is followed and $L_{t}^{D M}$ is the loss if discretion is exercised, given that private agents know that the mixed strategy has been adopted. From (13) and (29) it can be seen that:

$$
\text { (30) } L_{t}^{R M}=\left[\frac{(1+a)}{(a+q)} k-u_{t}\right]^{2}
$$

and

$$
\text { (31) } E_{t-1} L_{t}^{R M}-\frac{(1+a)^{2}}{(a+q)^{2}} k^{2}+V(u / R) \text {, }
$$

where $V(u \mid R)$ is the variance of u conditional on the rule, which is equivalent to being conditional on u being "small." Similarly, from equations (13), (14), and (28) it can be seen that:

(32) $L_{t}^{D M}=\frac{(1+a)}{a}\left[\frac{a}{(a+q)} k-\frac{a}{(1+a)} u_{t}\right]^{2}$

and

$$
\text { (33) } E_{t-1} L_{t}^{D M}=\frac{a(1+a)}{(a+q)^{2}} k^{2}+\frac{a}{(1+a)} V(u \mid D) \text {, }
$$

where $V(u \mid D)$ is the variance of $u$ conditional on discretion, which is equivalent to being conditional on u being "large." 
Combining these two branches of the loss function yields:

$$
E_{t-1} L_{t}^{M}=\frac{1+a}{a+q} k^{2}+q V(u \mid R)+\frac{(1-q) a}{(1+a)} v(u \mid D)
$$

Note from (18) that $E_{t-1} L_{t}^{M}=E_{t-1} L_{t}^{D}$ when $q=0$, since in this case $V(u \mid D)=V(u)$. Similarly, note from (20) that $E_{t-1} L_{t}^{M}=E_{t-1} L_{t}^{R}$ when $q=1$, since in this case $V(u \mid R)=V(u)$.

So far, our demonstration is simply a formalism. What we will show next is that under a range of parameter values the mixed strategy is superior to both the optimal rule and discretion. Since we simply want to show a possibility, an example will suffice. Recall (24) and consider a situation in which $u_{t}$ is uniformly distributed on the interval [ $\left.-U, U\right]$ such that $\mathrm{q}-\theta / \mathrm{U}$ for any choice of $\theta$ on the relevant interval. For this distribution, $V(u)=U^{2} / 3, V(u \mid D)=\left(1-q^{3}\right) U^{2} / 3(1-q)$ and $V(u / R)=q^{2} U^{2} / 3$. Furthermore, by substituting these conditional variances into (34) and minimizing $E_{t-1} L_{t}^{M}$ with respect to $q$, it can be shown that the optimal value of q must satisfy the condition: $1 /$

1 To obtain this condition, substitute the conditional variance expressions into (34) and set the derivative of this expression with respect to $q$ equal to zero. Rearrange the resulting expression so that it becomes:

$$
\mathrm{q}^{2} \mathrm{U}^{2}=\frac{2(1+a)^{2} \mathrm{k}^{2}}{(a+q)^{2}}
$$

from which equation (34) follows. 
(35) $q^{2}+a q-(1+a) k / U=0$.

The probability q need not be an object of choice, we are simply checking to see that if $q$ is chosen to minimize (34) then the resulting $q$ at the minimum is a number between zero and one. If the resulting $q$ is not between zero and one then it is impossible, in this example, for the mixing strategy to dominate both the optimal rule and discretion. If we find, however, that the value of $q$ that minimizes (34) does lie between zero and one, then we will have constructed an example where the mixing strategy is superior to both rules and discretion. Such an example arises when society places equal weight on output stabilization and price level stabilization (i.e., when $a=1$ in condition (13)), since in that case the unique positive root of $(35)$ is between zero and one when $k / U<1$. 1 / It should be noted that the mixed strategy is not always optimal. Indeed, if $\mathrm{k}$ is large or if $\mathrm{U}$ is small, the rule will dominate a mixed strategy. Note, however, that if $U$ is extremely large relative to $k$, then discretion has an advantage relative to the rule, but (as long as $k$ is positive) the mixed strategy will beat both the rule and discretion.

More generally, it should be emphasized that the support that such analysis provides for strategies that combine rules and discretion requires careful interpretation. In particular, the analysis does not

1 The reader should not interpret the moments of the $u$ distribution to be agreed upon numbers--they would be the subject of much dispute. Indeed, it seems to us to be a perfectly respectable position to claim that $u$ does not have any finite moments. Of course, such a position, while respectable, is not very helpful and we are proceeding as if the rules versus discretion disputants had agreed on a set of moments to use when discussing $u$. 
support the strategy of announcing a rule but not taking the rule seriously, as has sometimes appeared to have been the practice in the past. Rather, as we interpret the analysis, the mixed strategy calls for the authorities to follow a precisely defined rule in "normal circumstances", but to be prepared to override the rule in "abnormal circumstances". In implementing such a strategy, society would have to think carefully about how it wants to define "abnormal circumstances". Our example interpreted abnormal circumstances as synonymous with large and poorly understood shocks, but it might also be appropriate for the central bank to override the rule temporarily whenever the ultimate target variables had drifted too far off their intended course.

\section{Institutional Arrangements for Mitigating Credibility Problems}

Because we know from the time consistency literature that even authorities concerned solely with maximizing social welfare may be tempted to deviate from the optimal rule in the presence of distortions (recall Section II.4), it is important to establish mechanisms for overcoming monetary policy credibility problems. In some countries, the existence of independent central banks, and the practice of granting long and overlapping tenures to central bank governors, may provide an institutional framework within which an announced monetary policy strategy has more credibility than would be the case if monetary policy was controlled by elected officials with shorter terms of office. Nevertheless, even independent central banks have credibility problems in the sense that their announcements are not always accepted at face value. As emphasized above, monetary policy credibility problems could be 
easily resolved if the structure of the macroeconomic model was well known to all economic agents, if all relevant economic variables were observable, and if all disturbances to the economy could be characterized as having well defined probability distributions. In that case, society would derive no benefit from allowing the central bank to exercise discretion and, conversely, would have nothing to lose from resolving the monetary policy credibility problem by requiring the central bank to adhere rigidly to the optimal state contingent rule. By contrast, when the central bank has the opportunity to base the settings of its policy instruments on better information about the economy than private agents have (or had) in making contracts for wages and other relevant variables, eliminating monetary policy discretion can have the undesirable consequence of preventing central banks from performing a beneficial stabilization role.

In analyzing the difficulties that can arise in resolving monetary policy credibility problems when central banks have "private information"--i.e., different information than other economic agents can obtain or verify--Canzoneri (1985) has noted that "private information" includes both superior information about the economy and information about the policymaking process that the private sector cannot reconstruct. Our discussion in Section IV has emphasized that the policymaker's environment includes seldom-experienced events--such as wars, commodity price shocks, asset market panics, or horizon-expanding inventions--that are not amenable to any codification of policy reactions. In our view, it is this environment--superimposed on a world in which private agents find it rational (based on transactions and negotiations costs) to enter into 
contracts for wages and other variables for fixed periods of time in forms that are not fully state contingent or subject to continuous revision-that creates the possibility for discretionary central bank responses to seldom-experienced events to play a valuable stabilization role.

In considering the strategy of mixing a simple rule with discretion in the manner defined in the previous section, one of the important issues that arises is how to limit the exercise of central bank discretion when the circumstances in which discretionary responses are desired cannot be defined very precisely in advance. Our formal analysis relied on the assumption that the central bank was induced to minimize the sum of the social loss function plus a fixed cost that it incurred whenever it deviated from the rule. In practice, the achievement of an appropriate mix of rule and discretion seems likely to depend on: (1) the selection of a clearly-defined rule that can be expected to steer the economy in a direction broadly consistent with social preferences; (2) the appointment of central bankers whose preferences are closely aligned with those of society at large; and (3) the imposition of an appropriate penalty for deviating from the rule.

With regard to the first of these factors, many countries have allowed their central banks to operate with very imprecisely defined rules for monetary growth. For example: most monetary targets have been specified as ranges, few countries have adopted rules that preclude "drift" between targets for successive years, a number of countries have shifted their targeting strategies from one measure of money to another, and some countries have specified simultaneous targets for several monetary aggregates that cannot easily be controlled independently. Thus, 
in the context of the political viability that would come from an explicit understanding that rules would be mixed with discretion, there is scope for all countries to define their monetary rules more precisely. There also may be scope for adopting more sensible types of simple rules--for example, rules that prescribe explicit countercyclical behavior.

For some countries, the achievement of an optimal mix of rule and discretion might also be facilitated by changes in the process for selecting central bank governors. Rogoff (1985) has emphasized that in the context of a time-consistency problem, society can sometimes make itself better off by leaving monetary policy at the discretion of central bankers with preferences that attach more weight than the preferences of soclety at large to price level stabilization relative to output stabilization. By contrast, under the mixed strategy envisioned in this paper, society wants its central bankers to adhere rigidly to a rule under "normal" circumstances, and only to deviate from the rule when doing so provides a sufficient reduction in the value of the social loss function. Accordingly, in this set up, it seems desirable to appoint central bankers whose preferences are similar to those of society at large.

Finally, the issue of how severely to penalize central banks for exercising discretion to override the rule may be a matter that can only be decided through experimentation. At present, some countries subject their central bankers to regular cross-examinations by elected officials, but it is difficult for such procedures to discipline central bankers effectively when announced rules for monetary policy are not clearly defined. With a clearly defined monetary rule, the costs imposed by public cross-examinations and protestations might well dissuade central 
bankers from overriding the rule with much frequency. Regardless of whether public cross examination is sufficient for this purpose, however, the severity of the penalty (or the cross examination) should be inversely related, other things equal, to the level of confidence with which it is expected that the rule will steer the economy in a direction consistent with social preferences.

\section{The Choice of Variables for Monetary Rules}

The adoption of a mixed strategy for monetary policy might have an important bearing on the appropriateness of different choices of variables for monetary rules. This section first discusses the choice of variables for monetary rules in general, and subsequently considers how the arguments change when rules can be overridden in some circumstances.

\section{Conceptual distinctions}

Discussions of monetary policy strategies draw conceptual distinctions between three types of variables: policy instruments, intermediate variables, and ultimate target variables. A further distinction can be drawn between potential and actual policy instruments. Potential policy instruments are variables that the central bank has the ability to control precisely; actual policy instruments are potential instruments that the central bank chooses to control. Historically, monetary authorities have typically chosen as their actual policy instruments either a short-term market interest rate (such as the rate at which money market participants lend funds overnight) or the quantity of some subset of the central bank's liabilities (such as the aggregate reserves that commercial banks hold 
at the central bank). The exchange rate is also a potential policy

instrument that a central bank could control precisely by offering to buy or sel1 (while supplies lasted) unlimited quantities of foreign currency at whatever exchange rate level it wished to establish.

In theoretical discussions of the optimal design of monetary policy, the objectives and preferences of policymakers are generally conceptualized in terms of a policy loss function. 1/ The ultimate targets are the variables on which the value of the loss function directly depends. One of the two important classes of ultimate target variables includes measures of real economic performance, such as unemployment rates, gaps between actual and potential output, or rates of growth of real output. The other important class of ultimate target variables includes measures of price stability. The emphasis that theoretical analysis places on these two classes of ultimate targets seems to reflect popular sentiments. $2 /$

Bryant (1980) has identified four key characteristics that differentiate monetary policy strategies from each other. These characteristics are: (1) the choice of policy instruments; (2) the choice between a single-stage decision procedure in which instrument settings are linked directly to the values of ultimate target variables, or a multi-stage approach in which instrument settings are based on values

1) The discussion in this section ignores discrepancies between the preferences of policymakers and the preferences of society at large.

2) In the context of our minimally articulated rational expectations model, it is not obvious why the level of the inflation rate should have much direct weight in the social loss function. Nevertheless, price level stabilization is repeatedly emphasized as an important objective of society and its policy authorities. 
of intermediate variables (i.e., variables that are neither ultimate targets nor actual policy instruments, such as monetary aggregates that are defined to include more than the liabilities of the central banks);

(3) the choice of Erequency with which to review and possibly adjust the instrument setting; and (4) the choice of how to incorporate feedback from new information.

\section{Rules based on monetary aggregates}

Beginning in 1975, a number of major industrial countries began to experiment with multi-stage strategies in which central banks announced and pursued target growth rates (or growth rate ranges) for selected monetary aggregates as intermediate variables that were not directly under their control. 1/ Although this paper does not attempt to reconstruct the explanations that these countries provided when they turned to setting intermediate targets for money growth rates, it may be noted that advocacy of monetary aggregates targeting is typically based on: (1) the belief that the stock of money is reliably linked to ultimate target variables; and (2) the belief that central banks have the ability to control the stock of money indirectly by adjusting their policy ins truments.

The rationale for a multi-stage intermediate targeting approach can be better appreciated when it is recognized that in practice the objective of monetary policy is to achieve desirable outcomes for output and the price level over a multi-period horizon in a framework in which changes in the settings of policy instruments affect output and/or the

1) See Isard and Rojas-Suarez (1986) for a review of the experience with monetary aggregates targeting. 
price level with distributed lags. In reality, the authorities generally have fairly accurate information about contemporaneous measures of output and inflation, but confront major difficulties in forecasting how the future paths of output and inflation will evolve under different settings of their policy instruments.

The difficulty of forecasting the evolution of output and inflation, and of estimating the effects on these ultimate target variables of changes in monetary policy instruments, is one of the reasons that central banks in the mid-1970s found it attractive to adopt the mediumterm strategy of setting intermediate targets for the growth rates of monetary aggregates. It was felt that the effects of changes in policy instrument settings could be predicted more reliably, and that deviations from targets could be observed more accurately and corrected more quickly, when targets were specified in terms of the monetary aggregates rather than ultimate target variables. Moreover, it was felt that a medium-term strategy of gradually declining growth rates for monetary aggregates would be consistent with steady real output growth and gradually declining rates of inflation.

More than a decade of experience has now shown that monetary aggregates targeting was not as successful as the authorities had hoped it would be. Accordingly, central banks in most of the major industrial countries have been led to abandon or de-emphasize their intermediate targets for monetary aggregates. The growing disenchantment with monetary aggregates targeting has been largely attributed to (1) the instability of velocity (i.e., of the relationship between money and nominal GNP) in an environment of financial deregulation and innovation, and (2) the 
emergence of strong political pressures to use the instruments of monetary policy to resist "disruptive" movements in exchange rates following a period in which the extraordinary rise and fall of U.S. dollar exchange rates has subjected producers and consumers to major shifts in the terms of international competition.

\section{Other types of monetary rules}

As possible alternatives to rules based on monetary aggregates, it has been suggested that monetary rules could be formulated in terms of such variables as nominal interest rates or exchange rates, real interest rates or exchange rates, interest rates, the price level, real GNP or nominal GNP. Traditionally, discussions of the choice of variables for monetary rules has been based on a presumption that the authorities would adhere rigidly to the rule rather than pursuing the type of mixed strategy suggested in Section $V$.

Under the presumption that the rule would be applied rigidly, an argument that is often advanced against adopting a target for a nominal interest rate or a nominal exchange rate is that price explosions (or severe deflations) could occur if the authorities prevented nominal interest rates or exchange rates from adjusting following a rise (decline) in inflation or inflationary expectations. 1/ A strong argument against adopting a target for either a real interest rate or a real exchange rate is that the authorities could not provide an effective anchor against inflation by simply allowing changes in inflation or inflationary expectations to be incorporated completely into nominal interest rates or

1) See Gagnon and Henderson (1988) for a recent analysis of nominal interest rate pegging under alternative expectations hypotheses. 
nominal exchange rates. 1 / The main argument against targeting either the price level or the level of real GNP is that both variables matter: adopting a strategy that was concerned only with one of the two major classes of ultimate target variables could lead to undesirable outcomes for the other. In this context, proponents of nominal GNP targets have suggested that joint outcomes for real GNP and inflation would be preferable to what likely would be achieved under either real GNP targets or price level targets. Opponents of nominal GNP targets have argued, however, that such rules do not lead to desirable policy responses to "supply shocks" such as poor harvests or oil price shocks. In particular, an expansionary response to the loss in nominal GNP associated with an output shortfall could not increase the supply of output and would thus be inflationary, while a contractionary response to the increase in nominal GNP associated with a rise in the supply price of oil or other commodities would reinforce the recessionary effects of the price rise on aggregate demand.

The arguments change when the choice of variables for monetary rules is considered as part of a policy strategy in which a rule would be mixed with discretion. In this context, many of the arguments against the use of particular variables in monetary rules lose their force.

While a lengthy reconsideration of these arguments is beyond the scope of this paper, $2 /$ it may be noted that a target for nominal GNP or an exchange rate becomes more appealing when discretion can be exercised

1 See Adams and Gros (1986) for an analysis of the consequences of real exchange rate rules.

2f Our companion papers focus more extensively on nominal GNP rules and exchange rate stabilization strategies. 
in response to supply shocks. A consensus on a feasible and appropriate target for nominal GNP growth might be much easier to reach than agreement on either the appropriate macroeconomic model or the appropriate relative weights to attach to price level stability and real output growth in the social objective function. 1/ Moreover, while there are wide-ranging disagreements over the appropriate specifications of macroeconomic models in general, there appears to be considerably less disagreement about the reduced form relationship between base-money growth and nominal GNP. 2/

\section{Concluding Remarks}

During the 1980s, monetary authorities in the largest industrial countries have become more tolerant of variability in monetary growth rates relative to preannounced targets or projections, while giving increasing consideration to exchange rate objectives. $\underline{3} /$ Although the authorities have not modified their broad objective of maintaining appropriate conditions for sustained noninflationary growth, there are important unresolved questions about the appropriate strategy for pursuing that objective, particularly in the largest countries.

This paper has used a simple analytic framework to review and reconsider some of the basic issues that arise in designing and

1) See McCallum $(1987,1988)$ and Flood and Isard(1988) for discussions of (and counterfactual simulation experiments with) nominal GNP rules for the United States.

2) As McCallum (1987) notes, however, in the open economy context it might be preferable to specify a target for some measure of nominal aggregate demand other than nominal GNP.

3) Monetary policy strategies have also involved policy coordination among countries to encourage the depreciation of the U.S. dollar during a period following the Plaza Meeting of the Group of Five countries in September 1985, and to resist further large changes in exchange rates during the period since the Louvre Accord was announced in February 1987. 
implementing a strategy for monetary policy. Among the main points are the following.

1. Under the unrealistic assumption that both the monetary authorities and the private sector know the macroeconomic structure, can observe all relevant economic variables accurately ex post, and have accurate ex ante information about the probability distributions of disturbances to the economy, the optimal strategy is a state contingent rule rather than the type of non-state-contingent monetary targets that countries have adopted in the past. $1 /$ To the extent that time consistency problems exist in such a situation, the optimal state contingent rule can be made credible through institutional mechanisms to insure precommitment.

2. The resolution of credibility problems and the design of an optimal strategy become more complicated when there is considerable uncertainty about the economic structure and the nature of disturbances. On the one hand, the environment generates new information that can be used to continuously reevaluate the structure or structural parameters of the economy and the nature of economic disturbances; thus, there are important potential gains from allowing the central bank to make use of the latest available information in its attempts to stabilize the economy. On the other hand, when the environment includes seldom experienced events that are not amenable to any codification of policy reactions, it seems virtually impossible for the private sector to reconstruct the policymaking process. The credibility of monetary policy would be

1) It can also be shown, under this unrealistic assumption, that a fixed exchange rate strategy would not be optimal. 
questionable in such circumstances if the central bank announced a complicated state contingent procedure for setting its policy instruments and was allowed to use new information to make period-by-period revisions of the structural model and/or the parameter estimates on which its instrument settings were based.

3. While the problems associated with complicated state-contingent strategies in an environment of considerable model uncertainty have led some economists to propose the adoption of simple policy rules, a mixed strategy of combining a simple rule with discretion may be preferable both to rigid adherence to the rule and to complete discretion. The type of mixed strategy we are referring to here is not a strategy of announcing a rule but not taking the rule seriously, as has sometimes appeared to have been the practice in the past, but rather a strategy that calls for the authorities to follow a precisely defined (but simple) rule in "normal circumstances" and to override the rule only under certain types of conditions.

4. Institutional mechanisms that penalized central banks for exercising discretion might be important for resolving credibility problems under a mixed strategy, just as they might be for precommitting the authorities to adhere rigidly to a rule. In this context, existing institutional oversight arrangements (generally involving regular cross examinations of central bankers by elected officials) might be more effective if the rule component of the mixed strategy was defined precisely.

5. In the context of a mixed strategy involving a simple rule that can be overridden under certain types of conditions, many of the 
arguments against the use of particular variables in monetary rules lose their force. A rule for targeting nominal GNP, for example, becomes more attractive when the rule can be overridden in response to supply shocks. 


\section{References}

Adams, Charles and Daniel Gros (1986), "The Consequences of Real Exchange Rate Rules for Inflation: Some Illustrative Examples, "International Monetary Fund Staff Papers 33:439-76.

Barro, Robert J. and David B. Gordon (1983), "Rules, Discretion and Reputation in a Model of Monetary Policy, " Journal of Monetary Economics $12: 101-21$.

Bryant, Ralph (1980), Money and Monetary Policy in Interdependent Economies, The Brookings Institution, Washington, D.C.

Canzoneri, Matthew B. (1985), "Monetary Policy Games and the Role of Private Information," American Economic Review 75:1056-70.

Flood, Robert P. and Peter Isard (1988), "Simulations with a Rule That Links Base-Money Growth to Nominal GNP," forthcoming.

Gagnon, Joseph E. and Dale W. Henderson (1988), "Nominal Interest Rate Pegging Under Alternative Expectations Hypotheses," revised manuscript (July).

Gray, Jo Anna (1976), "Wage Indexation: A Macroeconomic Approach," Journal of Monetary Economics $2: 221-35$.

Isard, Peter and Liliana Rojas-Suarez (1986), "Velocity of Money and the Practice of Monetary Targeting: Experience, Theory and the Policy Debate." In International Monetary Fund, Staff Studies for the World Economic Outlook, Washington, D.C.:73-114.

Kydlund, Finn E. and Edward C. Prescott, "Rules Rather Than Indiscretion: The Inconsistency of Optimal Plans," Journal of Political Economy $85: 473-92$.

Lucas, Robert E., Jr. (1972), "Expectations and the Neutrality of Money," Journal of Economic Theory 4:103-24.

McCallum, Bennett T. (1987), "The Case for Rules in the Conduct of Monetary Policy: A Concrete Example." In Federal Reserve Bank of Richmond, Economic Review, Richmond:10-18 (Sept./Oct.). , (1988), "Robustness Properties of a Rule for Monetary Policy," revised manuscript (February).

Rogoff, Kenneth (1985), "The Optimal Degree of Commitment to An Intermediate Monetary Target," Quarterly Journal of Economics $100: 1169-89$. 
, (1987), "Reputation, Coordination and Monetary Policy," forthcoming in R. Barro (ed.), Handbook of Modern Business Cycle Theory, Cambridge University Press. 